\title{
Hairy Tongue in an Elderly Neglect Patient
}

\author{
Khurshid A Mattoo ${ }^{1 *}$ and Nagaraja $\mathrm{K}^{2}$ \\ ${ }^{1}$ Department of Prosthodontics, Jazan University, KSA \\ ${ }^{2}$ Department of Oral Medicine and radiology, Subharti University, India \\ *Corresponding author: Khurshid A Mattoo, Department of Prosthodontics, Jazan University, KSA
}

Received: 制 October 23, 2019

Published: 湝 October 30, 2019

\begin{abstract}
Elder neglect is an accepted social practice in the scientific domain and globally there is an increase in reporting of such association with medical diseases. Elder neglect results in depression and when antidepressant drugs are taken for a long period of time, adverse effects do result in one form or the other. We present a unique case of such complex social phenomenon in which an elderly patient was suffering from neglect which resulted in depression and manifested in the form of a hairy tongue on prolonged treatment with antidepressant drugs. These psychological associations are an important consideration in diagnosis and treatment planning of a clinically visible disease. The patient required prosthetic rehabilitation but forfeited the treatment midway.
\end{abstract}

Keywords: Elder abuse; Depression; Clozapine; Hyperkeratosis; THARA (illegally brewed alcohol)

\section{Introduction}

Suffering of elderly people at the hands of their abuser is not a new phenomenon. It has existed for centuries in various forms. With a growing human life span, the cases of elder maltreatment are expected to increase in the coming decades. Among various forms of elder maltreatment, elder neglect is common and has been shown to be present among the elderly patients visiting prosthodontist for prosthetic rehabilitation [1]. Such patients are bound to suffer from depression, which may vary from being mild to severe and may be untreated or under medication. Clozapine is an antipsychotic medication that is used as a maintenance treatment for psychotic depression in order to reduce the risk of tardive dyskinesia [2].

It is a drug that belongs to the same class as olanzapine, which is used for similar psychotic condition and has been reported to be associated with the development of black hairy tongue [3]. Black Hairy Tongue (BHT) (lingua villosa nigra, nephritis linguae) is a painless, benign disorder of the dorsum of the tongue that is a reactive hypertrophy of filiform papillae to the desquamation of the tongue surface. The hairy appearance of the tongue results from hypertrophied and elongated filiform papillae, which later encourages collection of fungi, bacteria and food debris [4]. The clinical presentation of the tongue is due to both extrinsic and intrinsic factors that range from alcohol intake, tobacco chewing, smoking, poor tongue hygiene, underlying medications or radiation therapy $[5,6]$.

This article is unique since it presents a case of black hairy tongue and leukoedema of buccal mucosa, in an elderly neglected patient who was under medication for depression.

\section{Case Report}

An elderly male patient aged 68 years, reported to department of oral medicine and diagnosis for replacement of missing mandibular teeth. A clinical diagnosis of black hairy tongue and leukoedema of buccal mucosa was made clinically (history, clinical feature) (Figure 1A \& 1B) which were later confirmed histologically (Figure 1C \& 1D). The patient was referred to the department of prosthodontics since the patient required replacement of his missing teeth. Since the patient's condition was not tidy a thorough history in the diagnosis of self-neglect was investigated before any treatment would commence. Elder neglect was investigated through an interview based on a written questionnaire.

The patient was consuming alcohol (Thara - a local brew of north india) since last ten years and using chewable tobacco for more than thirty years. The patient was taken to a psychiatrist by his son six months back, after which he was diagnosed with 
depression for which he was taking multiple medicine (fluoxetine, olanzapine). Patients dental status included worn down natural dentition, multiple carious teeth and fractured anterior left teeth (Figure 1A). The tongue showed hypertrophied papillae along with the presence of food debris and stains (Figure 1A). A distinctive white lesion was present on the left buccal mucosa in the region of the buccal vestibule extending more to the maxillary arch distal to the existing maxillary second molar (Figure 1B). The lesion was grayish white in color that had irregular borders on the occlusal plane level. Biopsy and oral exfoliative cytology were performed by the department of oral diagnosis to differentiate the existing condition from similar lesions (Figure 1C \& 1D).

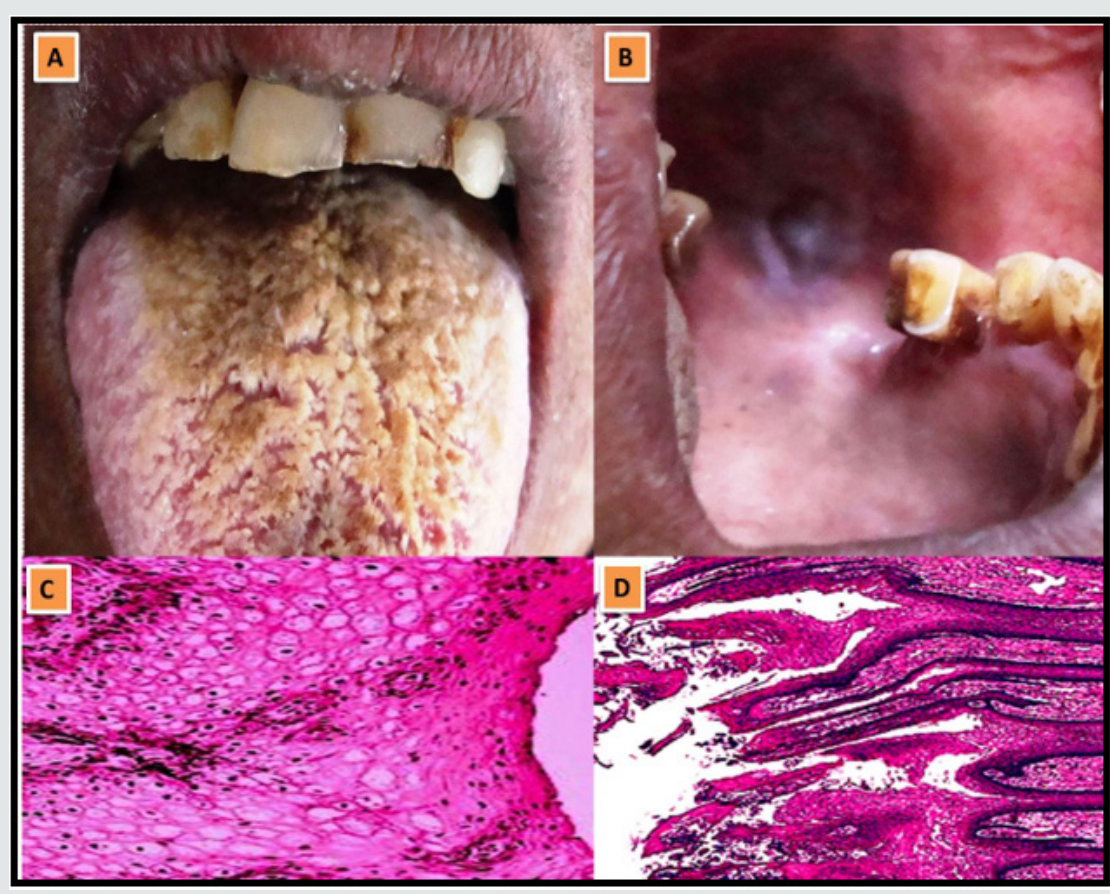

Figure 1.

\section{Discussion}

Elder neglect is not a new occurrence in social set up since it has existed since centuries. However, being a sensitive issue, it has mostly been brushed under the carpet, especially in conservative societies like Indians.

Urbanization shift from joint families to the nuclear family, death of spouse, transgenerational violence, isolation, caregivers stress and living arrangement are some of the factors that have been implicated in elder neglect [7].

However, one should differentiate between the self-neglect from elder neglect since self-neglect has different predisposing factors, although the two can be seen in combination [8]. in either case the subject is prone to develop oral and general health problems. The exact cause of black hairy tongue is still unknown.

However, there are some factors that have been implicated in the precipitation of the occurrence of such lesions. These include poor oral hygiene maintenance, chronic administration of topical or systemic antibiotics, alcohol consumption, excessive smoking or tobacco chewing and in some cases the use of mouthwashes $[9,10]$. depending upon the precipitating factors, the prognosis ranges from fair to excellent since it has been found to suppress the lesion with oral hygiene maintenance, systemic multivitamin therapy and surgical excision of the papillae $[9,10]$ the case presented in this article has given a history of depression since last six months and was on regular antidepressant medication. Olanzapine has been associated with development of hairy tongue in a few case reports $[3,11]$. In addition to antidepressant drugs, the condition has also been associated with chemotherapeutic drugs (temoxolomide, rituximab, methotrexate, procarbazine, and vincristine) [12], antibiotics (linezolid, tedizolid, vancomycin, penicillin, chloramphenicol) [13] and people who are addicted to drugs or alcohol.

The case presented in this article is unique since the patient was suffering from elder neglect from his children and has been taking the antidepressant medication since last 6 months but had developed the condition only a week back. While the same drug has been reported to be present within a week or two of the drug use. The clinical appearance of the lesion, although shows a very severe form of hairy tongue which is understandable since multiple factors that are associated with such clinical condition were a part of patients regular use (alcohol, smoking, poor hygiene)

\section{Conclusion}

Elder neglect is a scientifically accepted clinical condition that has been implicated in many systemic diseases as a predisposing factor.The presence of a hairy tongue in a neglected chronic alcoholic and smoker patient suffering from depression and taking antidepressant medicine is a complex phenomenon to conclude the cause effect relationship. 


\section{Acknowledgement}

The authors would like to acknowledge the efforts of the staff of the oral medicine and diagnosis for their prompt cooperation in carrying out the histological diagnosis.

\section{Conflict of Interest}

The authors hereby certify that they had no conflict of interest of any sort during the treatment of the patient or the reporting of its finding.

\section{References}

1. Mattoo KA, Shalabh K, Khan A (2010) Geriatric forensics: A dentist's perspective and contribution to identify existence of elder abuse among his patients. J Forensic Dent Sci 2(2): 81-85.

2. Jeyapaul P, Vieweg R (2006) A case study evaluating the use of clozapine in depression with psychotic features. Ann Gen Psychiatry 5: 20.

3. Tamam L, Annagur BB (2016) Black hairy tongue associated with olanzapine treatment: a case report. Mt Sinai J Med 73(6): 891-894.

4. Ma JS (2009) Teeth and tongue discoloration during linezolid therapy. Pediatr Infect Dis J 28(4): 345-346.
5. Vano Galvan S, Jaen P (2008) Black hairy tongue. Cleveland Clinic Journal of Medicine 75(12): 847-848.

6. Lawoyin D, Brown R (2008) Drug-induced black hairy tongue: diagnosis and management challenges. Dent Today 27(1): 62-63.

7. Mattoo KA, Kumar S, Khan A (2009) Prevalence of elder abuse among completely edentulous patients seeking complete denture prosthesis. J Ind Acad Geriat Dec 5(4): 177-180.

8. Nagaraj K, Mattoo KA, Brar A (2014) Self-Neglect associated with a patient having oral cancer. J Med Sci Clin Res 2(10): 2543-2546.

9. Heymann WR (2000) Psychotropic agent-induced black hairy tongue. Cutis 66(1): 25-26.

10.Langtry J, Carr M, Steele M, Ive F (1992) Topical tretinoin: a new treatment for black hairy tongue (lingua villosa nigra). Clinical and Exp Dermatol 17(3): 163-164.

11. Kanodia S, Giri VP, Veerabhadrappa RS, Giri OP, Shankar VN (2017) Black hairy tongue with olanzapine: A rare case report. Indian Journal of Psychiatry 59(2): 249-250.

12. Yamagishi Y, Maruyama K, Kobayashi K, Kume S, Sasaki N, et al. (2017) Black hairy tongue after chemotherapy for malignant brain tumors. Acta Neurochir 159(1): 169-172.

13.Abdollahi M, Radfar M (2003) A review of drug-induced oral reactions. J Contemp Dent Pract 4(1): 10-31.
This work is licensed under Creative Commons Attribution 4.0 License

To Submit Your Article Click Here: Submit Article

DOI: 10.32474 /MADOHC.2019.03.000178

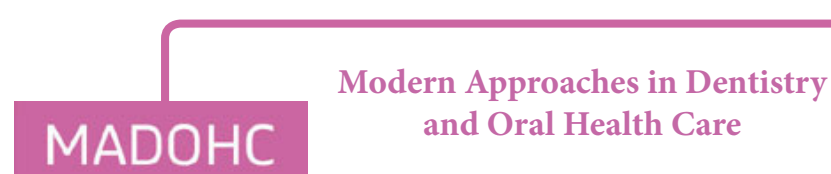

Assets of Publishing with us

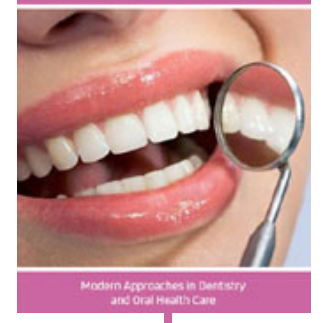

- Global archiving of articles

- Immediate, unrestricted online access

- Rigorous Peer Review Process

- Authors Retain Copyrights

- Unique DOI for all articles 